\title{
The Politics of Computer Music
}

\author{
Fernando Iazzetta ${ }^{1}$ * \\ ${ }^{1}$ NuSom - Núcleo de Pesquisas em Sonologia - Departamento de Música da Universidade de São Paulo \\ Av. Prof. Lúcio Martins Rodrigues, 443 - Butantã, São Paulo - SP, 05508-020
}

iazzetta@usp.br

\begin{abstract}
When a set of objects, actions, and procedures begin to coalesce and gain some coherence, they become perceived as a new, cohesive field. This may be related to the emergence of a new discipline, a new craft, or a new technological configuration. As this new field shows some coherence and unity, we tend to overlook the conditions that gave rise to it. These conditions become "naturalized" as if they were inherent in that field. From this point on, we do not wonder anymore to what extent the contingencies (formal, social, economic, technological, aesthetic, religious) that gave rise to that field have been crucial to its constitution.

When it comes to computer music we are comfortably used to its applied perspective: tools, logical models, and algorithms are created to solve problems without questioning the (non-computational) origin of these problems or the directions taken by the solutions we give to them. The idea of computing as a set of abstract machines often hides the various aspects of the sonic cultures that are at play when we develop tools and models in computer music. The way we connect the development of computer tools with the contingencies and contexts in which these tools are used is what I call the politics of computer music. This connection is often overshadowed in the development of computer music. However, I would like to argue that this connection is behind everything we do in terms of computer music to the point that it often guides the research, development, and results within the field.
\end{abstract}

\section{General Information: Full papers}

First of all, I'd like to thank the organization of the SBCM for the invitation to deliver this talk. Having had the opportunity to participate in the first edition of this conference back in 1994, I am honored to be here, 25 years later, to share some ideas with this computer music community.

Before I start I want to make a warning. This text do not reflect the point of view of a computer scientist, but the one made by an artist and teacher who has developed a close relationship with computer music technology. Taken from this perspective, this text could be fairly titled: How I Understand Computer Music and What I Would Like It to Do For Me.
I want to begin talk by addressing the two pictures below. They both refer to the use of technology in works that are part of our artistic production at NuSom, the Research Center on Sonology at the University of São Paulo.

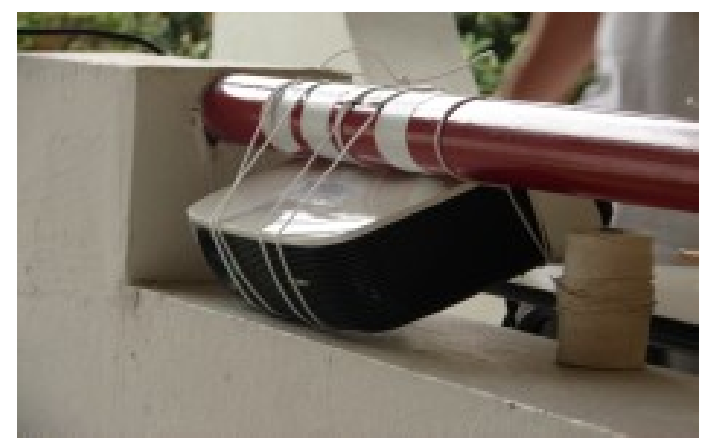

Figure 1: Photo from ¿Música? 2 (2009)

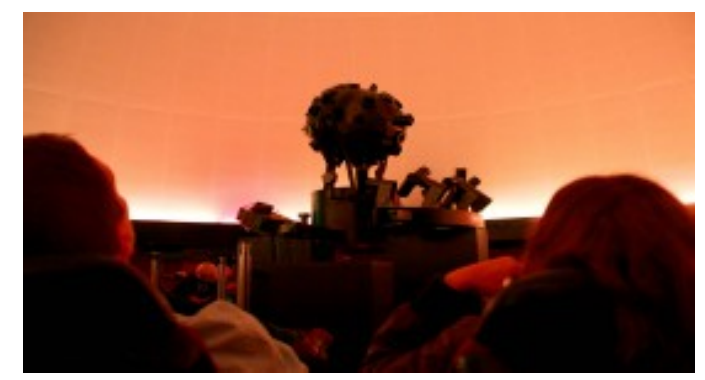

Figure 2: Photo from ${ }_{\dot{C}}$ Musica? 14 (2019)

Both pictures are taken from performances produced by NuSom in a series os events called ¿Musica?. The series was created as a way to provoke the discussion about academic practices at the Department of Music at the University of São Paulo, which, like most music departments in the country, focuses on concert music from the European tradition. The series started in 2006 and currently is in its 16th edition.

What connects these two images is not the use of digital technologies in a music performance, nor the fact that they show two video projectors. What interests me about them is how they can reveal the context in which

* Supported by CNPq, proc. \# 309143/2018-7. 
they were used.

The first image is somehow explicit: a video projector tied with strings is not just an unusual technical solution. It indicates the coexistence between hi and lowtech, between sophistication and the gambiarra.

The second refers to a concert we gave last April at the Planetarium of São Paulo and may require some explanation. The choice of the Planetarium to perform that concert was not only aesthetic, but also political. This is a remarkable facility, opened in 1957, which is part of São Paulo's cultural life. But in recent years it only works twice a week because it relays on a rather reduced staff and on a very small budget. In this constraint scenario the Planetarium cannot maintain a more intense regular schedule. Therefore, choosing this site to present the performance had more to do with giving visibility to it than to the fact that it offers and amazing and sophisticated setup of video projectors.

I began by bringing these two examples because they refer to concrete technological problems, even though these problems do not concern how these machines work nor the techniques that are involved in their operation.

This kind of circumstance constantly induces and regulates the actions and decisions we make when we create and use a technology, but we rarely think of these issues as technological problems in themselves. However, I can only understand technology as a device that acts on something and has an agency. We do things with them. But to a large extent they also make us to be the way we are and to act the way we do.

\section{Computer Music}

There is nothing new about this approach and it may be slightly related to what has been called material culture studies: the study of usage, consumption, creation, and trade of objects as well as the behaviors, norms, and rituals that the objects create or take part in.

When a set of objects, actions, and procedures begin to coalesce and gain some coherence, they become perceived as a new, cohesive field. This may be related to the emergence of a new discipline, a new craft, or a new technological configuration. As this new field shows some coherence and unity, we tend to overlook the conditions that gave rise to it. These conditions become "naturalized" as if they were inherent in that field. From this point on, we do not wonder anymore to what extent the contingencies (formal, social, economic, technological, aesthetic, religious) that gave rise to that field have been crucial to its constitution.

Of course, as the field develops in time we have the impression that its concerns, methods and tools change accordingly. It seems that there is a direct relation between the emergence of new problems and the development of new solutions (techniques, technologies, methods).
When it comes to computer music we are comfortably used to its applied perspective: tools, logical models, and algorithms are created to solve problems without questioning the (non-computational) origin of these problems or the directions we take when finding solutions to them. The idea of computing as a set of abstract machines often hides the various aspects of the sonic cultures that are at play when we develop tools and models in computer music.

The way we connect the development of computer tools with the contingencies and contexts in which these tools are used is what I call the politics of computer music. This connection is often overshadowed in the development of computer music. However, I would like to argue that this connection is behind everything we do in terms of computer music to the point that it often guides the research, development, and results within the field.

When we disregard this connection (this politics) we pretend that our choices are neutral in terms of ethics and, particularly in the case of computer music, in terms of aesthetics as well.

In this text, I would like to consider the politics of computer music as a way to critically explore the field. After more than 2 decades working in this area which is loosely called "music and technology" - and technology here is often taken as a synonym with computing - it seems to me that there is no point in thinking computer music without thinking its politics. This is obviously a personal position, which I would like to share with the reader, without it implying any disregard for other forms of action in the field.

I regard technology not only as a tool we use to accomplish something. A technology is a way of thinking. It contains in its modes of operation a frame of what will be done and how it will be done. Roland Barthes [1], referring to Russian linguist Roman Jákobson, has already said that language - one of our most fundamental technologies - is defined much more by what it forces us to say than by what it allows us to say. Instruments, software and machines are not passive means. As Thomas Hankins and Robert Silverman point in their book about instruments and the imagination, "Instruments have a live of their own. They do not merely follow theory; often they determine theory, because instruments determine what is possible, and what is possible determines to a large extent what can be taught". [2]

When I choose to use or produce a tool I am choosing a way of thinking (aesthetics, poetics) and a way of acting (ethics, politics). Therefore tools simultaneously occupy and configure a place and a time. They set up a context, but the context also determines what technology is, the agency it produces.

History is full of examples of how certain technologies acquire new perspectives when changing the 
context in which they are used. Thomas Edson could not foresee the use of his phonograph as a music tool when he wrote the device's patent 1878 . But, by the end of the nineteenth century the phonograph was already thought of as a musical instrument.

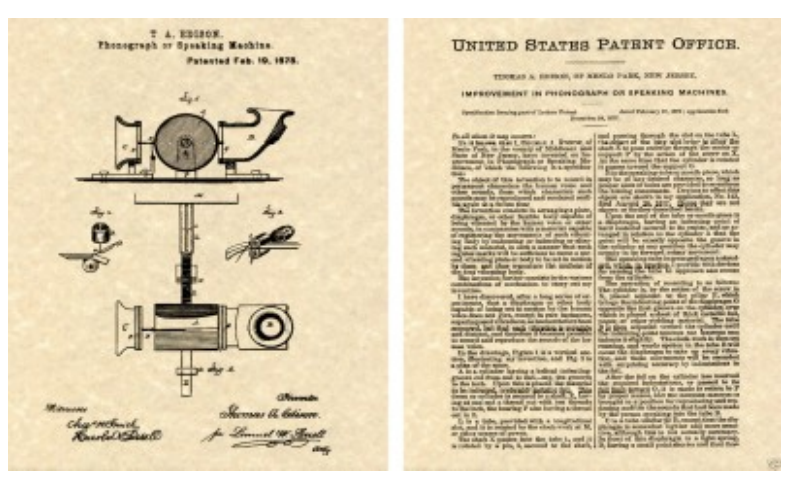

Figure 3: Thomas Edison's 1877 Phonograph Patent

Another prominent inventor, the Brazilian Santos Dumont, got depressed when who saw his invention, the airplane, been used to kill people in the First World War instead of helping to connect them.

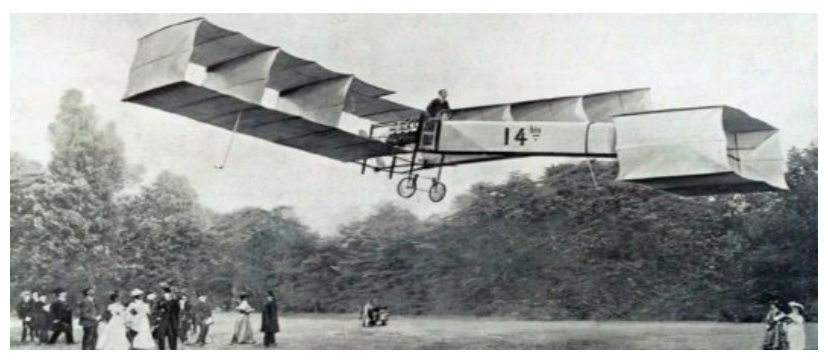

\section{Figure 4: Santos Dumont's famous airplane 14 Bis}

The same could be said about the profound discomfort of Christopher Cerf, the musician who composed about 200 songs for the educational TV show Sesame Street when he discovered that his children's songs were used as one of the most terrible forms of torture in Guantanamo Prison.

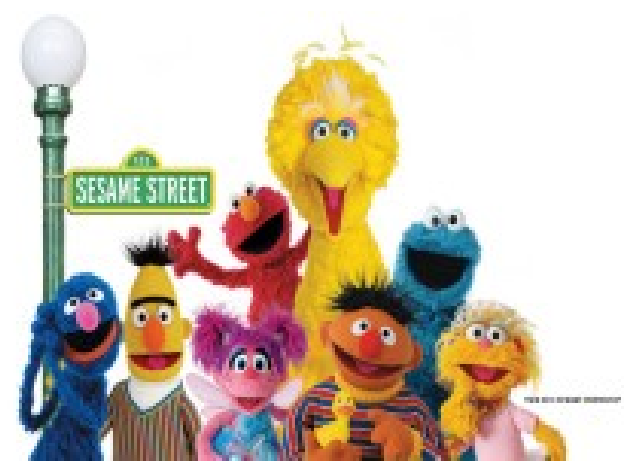

Figure 5: Sesame Street Show

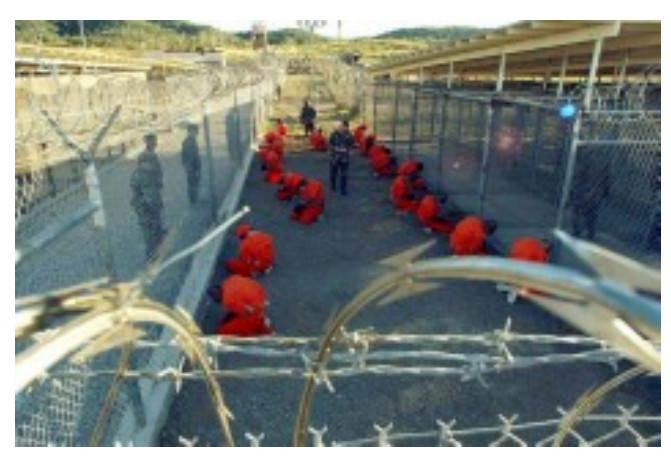

Figure 6: Guantanamo Prison

\section{The SBCM}

So lets try to bring the discussion to the local context of Brazilian computer music and take a look at some aspects that influenced the field in Brazil through the critical lenses of its politics.

In 1994 a friend of mine, professor Mauricio Loureiro, suggested me to submit a work to a computer music conference he was organizing. It was the first edition of this conference, the Brazilian Symposium on Computer Music. Looking back at it I now realize how remarkable this meeting was. It gathered some wellknown names of the field such as Francisco Kropfl, David Jaffe, Xavier Serra and Stephen Travis Pope in a very intense meeting. Although there were many people involved in this endeavor, I must credit the success of the event to its Chair, Mauricio Loureiro.

I understand that this first SBCM represented the beginning of a systematic work on computer music in Brasil. As one might expect, this early phase was based on models inspired by other major research centers in the area such as IRCAM, CRRMA, or the Institute of Sonology (The Hague).

In fact, to some extent SBCM mirrored itself to the structure of similar conferences, especially the ICMC. This initial effort was undoubtedly one of the factors that contributed to the growth of computer music in Brazil and enabled the exchange with researchers and groups from other countries, specially from Latin America and the United States. Indeed, it would be difficult to think of a field of computer music today that would remain outside of a global perspective that involves not only sharing common problems and technologies, but also moving through a network of conferences, publications, exchanges between research groups and eventually sharing funding.

On the other hand, I understand that this adherence to these existing models should be counterbalanced by an investigation of the particularities of the Brazilian socio-cultural context. 


\section{The Musarts}

I just want to give an example of how decisive the political and social environment can be when we decide to develop something around technology. In 2003, the scientific director of the São Paulo Research Foundation (Fapesp) had the opportunity to visit Ircam during a trip to France. He was impressed by the connection between art, science, and technology promoted at the center and upon returning to Brazil, he proposed to a group of scholars from São Paulo the creation of a research center inspired by the French institute. Despite the significant differences between the cultural and economic realities of Brazil and France, the technocentric and scientificist model taken as representative of Ircam's mode of action seemed extremely appealing to Fapesp.

As one can imagine, it is not every day that an agency like Fapesp decides to allocate to a field such as computer music resources similar to those it allocates to the study of cancer treatment or to support the construction of communication satellites. This Brazilian Virtual Institute of Music and Technology was named MusArtS - Musica Articulata Scientia - but for various reasons, including lack of consensus among the researchers involved in the project, it was never implemented. But I suspect that Musarts did not succeed just because we didn't take into account the remarkable differences between French and Brazilian environments.

\section{Computer Politics}

Besides social cultural and economic differences, the way computers were introduced in Brazil occurred in a very particular way (this topic has been developed in [3]. From the 1990s, two events are significant to an understanding of the expansion of the area of music and technology in the country. 1 The first concerns a series of restrictions on imports of various items that were not manufactured in the country. These restrictions were supported by market reserve policies that were intended to protect the local industry from competition from developed countries. These restrictions had been applied since Estado Novo in the 1930s, but were intensified during the military dictatorship in the 1960s and 1970s. In spite of the rich Brazilian musical production, especially in the field of popular music, access to imported audio equipment and instruments (acoustic or electronic) was very restricted, which generated an informal (and illegal) market of considerable dimensions to feed the demand from this local music industry.

The Política Nacional de Informática (PNI [National Informatics Policy]) was established in 1984, also with the idea of stimulating the development of the computer industry in Brazil by forcing a market reserve for national capital companies. In general, its effects were not as expected: the sector developed poorly and consumers were forced to pay exorbitant prices for obsolete products compared to the technologies available in other countries. In practice, Law No. 7,234/84, which reserved for domestic capital manufacturers the right to produce and sell computer goods, did not last long. Unable to meet the demand for computers and programs, the market reserve was revised in 1991 and abolished in 1992. But, in its eight years it paved the way for the creation of countless Brazilian companies, leaving behind a trail of controversy.

From the 1990s, access to digital technology was gradually established, and that had a direct impact on the emergence of new studios focused on computer music production. This process coincided with the increasing digitalization of musical and sound production, making audio technologies significantly cheaper. In the following decade, significant investments were made to consolidate digital inclusion policies. Pontos de Cultura (PdC [Points of Culture]) was an initiative of the Ministry of Culture in the government of Luiz Inácio Lula da Silva that reflected a series of changes in the prospects of cultural production fostering. The PdC aimed to provide direct funding to community groups and non-governmental entities to develop activities in local communities. There was not one single model, in order to avoid the homogenization of actions that extended to quite different sectors and contexts. Based on the ideas of autonomy and empowerment, the program exposed its clearly Marxist foundations to promote an increase in the cultural production of a sector of the population that was historically disenfranchised from institutional support mechanisms. From indigenous communities in remote areas to organized groups in the large urban centers of the country, a network was established whose main characteristic was, perhaps, diversity. It is important to note that part of the funds allocated to each PdC project was destined for purchasing a multimedia station (a mini audio-recording studio, a small video-editing station, and computers using free software). Multiplied by the thousands, the PdC projects provided access for an invaluable number of young people from different social strata to audiovisual production equipment, thus increasing production, especially in the less-favored sectors of Brazilian society. With that, a whole generation of artists formed outside the commercial circuits and distant from the support of the academy, to become a protagonist in the arts field. The impact of this cultural effervescence reverberates in the current period with the formation of a rich experimental scene that attracted little attention from academic research in computer music. Again, more global concerns seemed to guide our attention.

\section{The NuSom}

I would like take this opportunity to briefly present the work being done by NuSom in recent years. The Center houses several groups that operate with some autonomy in different fields. Some are more linked to artistic practice, others to theoretical reflection and still others to technological development.

For the last 15 years we have produced a considerable amount of artistic and academic work in which the use of computational technologies is quite 
significant. A central question for the group's work is how to make artistic production, academic research and technological development compatible. Several projects were developed in this sense, in collective and individual works.

Particularly in the ¿Música? Series (see [4] and [5]) there is a strong concern about the employment and the development of technologies when they are taken into the artistic process which often implies a questioning regarding a positivist and scientific perspective of the use of these technologies. Similarly, the exploration of unusual spaces for artistic practice (¿Música? 6), or the incorporation of scenic, visual and textual elements (¿Música? 1 and 2), are always accompanied by critical discussions about these modes of production. For this reason, several works are built around themes that are discussed and studied in advance by the group. These themes may vary from abstract concepts - such as political militancy (¿Música? 12 and 13); the use of silence as musical material (¿Música? 11); mediation between the visual and the sound domain (¿Música? 3); or the exploration of improvisation techniques (¿Música? 8). There is constant care with the registration of these works, which will be discussed after they are submitted. These discussions, in turn, will feed the group's upcoming productions. That is, we seek to build a circular process in which research feeds artistic production and artistic production is taken as material for academic research itself.

This feedback between research, creation and reflection implies a process of constant evaluation of the role of technologies within the group's production. Computational tools are not taken as neutral elements, but as critical elements of the creative processes. In fact, the realization of artistic works is not taken as a neutral action that is referred only to the art world (art for the art sake), but as an aesthetic action that implies a political expression. Thus, the use of technologies, as a significant part of the group's poetics, is also subjected to a reflection on its ethical and aesthetic consequences. I take Nuson's artistic production not because it should be taken as an exemplary model of how one should deal with the political aspect of technology. On the contrary, my intention is to point out some of the tensions and contradictions that are at stake when we use music technologies without taking into account the contexts, the stories, and the contingencies in which they were created. The risk is that they rule the creative process and hide our own stories and our own aesthetic thinking.

\section{References}

[1] Barthes, Roland (s/d). Aula. São Paulo: Cultrix [originaly published in French in 1978].

[2] Hankins, Thomas \& Robert Silverman (1995). Instruments and the Imagination. New Jersey: Princeton University Press.

[3] Iazzetta, Fernando (2019). "Sounds from Elsewhere: Episodes for a History of Brazilian Sound Art." In Making it Heard: a History of Brazilian Sound Art (R. Chaves \& F. Iazzetta, Eds.). New York: Bloomsburry, 1242.

[4] Iazzetta, Fernando \& Lílian Campesato (2019). "La Serie ¿Música? Arte sonoro desde contextos locales”. I Simposio Internacional de Arte Sonoro: Mundos Sonoros: cruces, circulaciones, experiencias. Buenos Aires: Untref, 143-152.

[5] Kisil, Vitor (2014). ¿Música?: processos e práticas de criação e performance em um ambiente de pesquisas em sonologia, PhD Thesis, Departamento de Música, Universidad de São Paulo. 